\title{
Frequency and Prioritization of Patient Health Risks from a Structured Health Risk Assessment
}

Ann Fam Med 2014;12(6):iii. doi: 10.1370/afm.1732.

The Annals of Family Medicine encourages readers to develop a learning community of those seeking to improve health care and health through enhanced primary care. You can participate by conducting a RADICAL journal club and sharing the results of your discussions in the Annals online discussion for the featured articles. RADICAL is an acronym for Read, Ask, Discuss, Inquire, Collaborate, Act, and Learn. The word radical also indicates the need to engage diverse participants in thinking critically about important issues affecting primary care and then acting on those discussions. ${ }^{1}$

\section{HOW IT WORKS}

In each issue, the Annals selects an article or articles and provides discussion tips and questions. We encourage you to take a RADICAL approach to these materials and to post a summary of your conversation in our online discussion. (Open the article online and click on "TRACK Comments: Submit a response.") You can find discussion questions and more information online at: http://www.AnnFamMed.org/AJC/.

\section{CURRENT SELECTION}

\section{Article for Discussion}

Phillips SM, Glasgow RE, Bello G, et al. Frequency and prioritization of patient health risks from a structured health risk assessment. Ann Fam Med. 2014;12(5):505-513.

\section{Discussion Tips}

This paper presents useful information on (a) patient priorities in addressing their health behaviors and (b) the frequency of health risks in primary care. Do the data make a compelling case in support of an integrated care approach?

\section{Discussion Questions}

- What question is asked by this study and why does it matter?

- How does this study advance beyond previous research and clinical practice on this topic?

- How strong is the study design for answering the question?

- To what degree can the findings be accounted for by:

1. How patients were selected or how many chose to participate?

2. How the main variables were measured?

3. Confounding (false attribution of causality because 2 variables discovered to be associated actually are associated with a 3 rd factor)?

\section{Chance?}

5. How the findings were interpreted?

- What are the main study findings?

- How comparable is the study sample to similar patients in your practice? What is your judgment about the transportability of the findings?

- What contextual factors are important for interpreting the findings?

- How might this study change your practice? In particular, will the study inform your approach to helping patients identify and address specific health risks?

- How might this study change policy? Education? Research?

- Who are the constituencies for the findings, and how might they be engaged in interpreting or using the findings?

-What researchable questions remain?

\section{References}

1. Stange KC, Miller WL, McLellan LA, et al. Annals Journal Club: It's time to get RADICAL. Ann Fam Med. 2006;4(3):196-197. http:// annfammed.org/cgi/content/full/4/3/196. 